\title{
Escritores da liberdade: autobiografias de escravos, impressos e História da Educação
}

\author{
Alexandra Lima da Silva ${ }^{1}$
}

\begin{abstract}
Resumo
Explorar as narrativas de vida de ex-escravos nascidos no século XIX, nos Estados Unidos, é o horizonte do presente trabalho. O conjunto documental abarca os escritos de sujeitos como Frederick Douglass (1818-1895), Booker Washington (1856-1915) e Harriet Jacobs (1813-1897). Busca-se interrogar os sentidos da educação na vida de homens e mulheres que vivenciaram a escravidão, a fim de refletir sobre a importância do registro escrito e da leitura na experiência de tais sujeitos. $\mathrm{O}$ artigo sinaliza para as escassas autobiografias de escravos publicadas e impressas em língua portuguesa, e também para os poucos estudos no âmbito da História da Educação que fazem uso das autobiografias de escravos e libertos como fonte e/ou objeto de estudo. Investigar trajetórias como as de Harriet Jacobs, Frederick Douglass e Booker Washington é um caminho essencial para uma História da Educação, no plural.
\end{abstract}

Palavras-chave: Autobiografias; escravos; História da Educação.

1 Faculdade de Educação/UERJ. 


\title{
Freedom writers: slave autobiographies, printed and History of Education
}

\begin{abstract}
This study analyzes the slave narratives in the nineteenth century in the United States. The set of documents includes the writings of individuals such as Frederick Douglass (1818-1895), Booker Washington (1856-1915) and Harriet Jacobs (1813-1897). It seeks to examine the meanings of education in the lives of men and women who experienced slavery in order to reflect on the importance of the written record and reading in such subjects experience. The paper points to the few autobiographies of slaves published and printed in Portuguese and the few studies within the History of Education that explore the slaves' autobiographies and freedmen as a source and / or object of study. Investigate trajectories such as Harriet Jacobs, Frederick Douglass and Booker Washington is an essential way for the History of Education in the plural.
\end{abstract}

Keywords: Autobiographies; slaves; History of Education.

\section{Introdução: caminhos da liberdade, caminhos de pesquisa}

A publicação de autobiografias, em língua inglesa, de pessoas nascidas no cativeiro não é novidade (BLASSINGAME, 2007; OLNEY, 1990; DAVIS, 1985, RAWICK, 1972). Entretanto, no Brasil, são escassas as narrativas de vida de ex-escravos impressas em periódicos ou em livros. As poucas existentes são traduções de livros editados anteriormente em inglês. É o caso de Meus anos de cativeiro e de liberdade, autobiografia de Frederick Douglass, traduzida e publicada, em partes, no periódico Gazeta da Tarde, durante dois meses, em 1883.

Em 1940, ocorreu a publicação de Memórias de um negro, de Booker Washington; e, em 1988, o lançamento de Incidentes da vida de uma escrava, contados por ela mesma, de Harriet Jacobs. Por sua vez, An Interesting Narrative. Biography of Mahommah G. Baquaqua (1854) é considerada a única autobiografia impressa escrita por um escravo que viveu por 
um tempo no Brasil. Segundo a revista Carta Capital, a previsão para o lançamento do livro em língua portuguesa era o primeiro semestre de $2016^{2}$.

Outras escritas em primeira pessoa podem ser consideradas fontes para se pensar a experiência dos nascidos em cativeiro no Brasil. Esse é o caso do manuscrito Histórico Social (1876-1912), esboço autobiográfico de João de Mattos - padeiro, nascido escravo - objeto de dissertação de mestrado (CARVALHO, 2009). As vozes dos nascidos no cativeiro estão presentes em registros diversos, relatados em primeira pessoa (HAGER, 2013), tais como cartas (WISSENBACH, 2002; GRAHAM, 2007; MOTT, 1979), testamentos, inventários e petições (PAIVA, 2009). Todavia, por que publicar autobiografias de escravos?

O presente trabalho procura analisar a importância das autobiografias de escravos e a riqueza de tais fontes para a História da Educação. Através dessas histórias de vida, é possível compreender o significado do acesso à educação e ao universo da cultura letrada, na experiência desses homens nascidos na condição de escravos, e os caminhos empreendidos por eles até a conquista de ascensão social. Quais os significados do domínio da cultura letrada e os inúmeros escritos publicados por tais sujeitos em busca de uma emancipação plena da população afrodescendente nos Estados Unidos da América? Afinal, qual a importância do conhecimento da escrita para pessoas nascidas no cativeiro? É possível afirmar que tais textos possuem uma dimensão pedagógica? Se, por um lado, são escassas as autobiografias de escravos e libertos publicadas e impressas em língua portuguesa, são escassos também, no Brasil, os estudos no âmbito da História da Educação que fazem uso desse material como fonte e/ou objeto de estudo.

É importante salientar que a historiografia da Educação no Brasil traz importantes contribuições para o debate acerca da educação da população afrodescendente (nascida livre, escrava ou liberta). Conforme indicado por Surya Aaronovich Pombo de Barros (2005b), um dos caminhos possíveis para o estudo de tal questão pode ser justamente o 
uso de fontes de cunho autobiográfico, pois tais fontes trazem elementos para se pensar os distintos processos de escolarização e trazem à tona a presença negra na escola, que nem sempre era vista de forma otimista ou positiva.

Ao explorar o relato autobiográfico de Helena Morley, por exemplo, Surya de Barros evidencia o olhar receoso da normalista em ter que lecionar para crianças negras, lamentando: "que será de mim se for obrigada a largar a Escola, estudo, minhas colegas e tudo para ir ensinar a meninos pretos e burros no Rio Grande?" (BARROS, 2005b, p. 8). Ou em outro momento, quando explora o relato de Helena Morley para indicar a existência de professores negros: "como se pode ser tão bom como o nosso professor Dr. Teodomiro!? Depois meu pai ainda diz que gente escura não presta! Na Escola, pelo menos, os melhores são ele e Seu Artur Queiroga. Os brancos são crus de ruindade" (BARROS, 2005b, p. 8).

A preocupação com o problema da educação da população afrodescendente (que não significa, necessariamente, população escrava) é crescente na historiografia da Educação brasileira - o que se evidencia através de publicações de artigos, trabalhos em eventos e livros, frutos de pesquisas desenvolvidas em programas de pós-graduação no país. Dentre os trabalhos sobre a temática, trago alguns para o debate.

O problema da escolarização em uma sociedade escravista foi explorado por Adriana Silva, na análise feita a partir da experiência do professor negro Pretextato e da escola exclusiva para negros e pardos na Corte Imperial (SILVA, 2002). Na perspectiva de Cynthia Greive Veiga, a presença de pobres e negros na escola pública foi um advento do governo imperial (VEIGA, 2008). Já as tensões e os conflitos em torno da escolarização no período da abolição e da pós-abolição no Rio de Janeiro foi o tema central das análises no artigo "Felismina e Libertina vão à escola: notas sobre a escolarização nas freguesias de Santa Rita e Santana (Rio de Janeiro, 1888-1906)" (SCHUELER; RIZZINI; MARQUES, 2015).

Por sua vez, a dissertação de mestrado de Surya Aaronovich Pombo de Barros, defendida em 2005, explora os caminhos da escolarização da população negra em São Paulo, no período de 1870-1920 (BARROS, 2005a). No mesmo ano de 2005, Adlene Arantes explorou o papel da 
Colônia Orfanológica Isabel, localizada na província de Pernambuco, na educação de meninos negros, brancos e índios, no período de 1874 a 1889 (ARANTES, 2005). Defendida em 2007, a tese de doutorado de Marcus Vinícius Fonseca analisa a presença de pretos, pardos, crioulos e "cabras" nas escolas mineiras do século XIX, a partir do uso de documentação censitária (FONSECA, 2007). Importante também citar o estudo de Graciane Sebrão, que verificou instituições como a Escola de Aprendizes Marinheiros, o Asilo da Santa Casa de Misericórdia, as escolas noturnas e o Liceu de Artes e Ofícios, que exerceram o papel de escolarizar os negros, inclusive escravizados (SEBRÃO, 2015).

Especificamente sobre a educação de escravos e libertos, ainda há muito o que interrogar e investigar, no sentido de se dar visibilidade às experiências diversas. A atual Escola Municipal Luiz Delfino, localizada no bairro da Gávea, cidade do Rio de Janeiro, é exemplo de instituição centenária que carrega a memória de ter sido "uma escola para escravos". Ainda em funcionamento, a instituição foi criada, em 1861, por Zé Índio, um ex-escravo letrado que atuava como mestre das crianças da fazenda de Pedro Pereira da Silva. Ainda no século XIX, a escola foi apadrinhada por D. Pedro II, recebendo o título de Escola do Imperador (RIO DE JANEIRO, 2005, p. 45).

No âmbito das pesquisas acadêmicas sobre a questão, destaco a dissertação de mestrado de Katia Geni Cordeiro Lopes (2012), que examina a Escola da Imperial Quinta da Boa Vista, no bairro Imperial de São Cristóvão, Zona Norte do Rio. Era um dos espaços de instrução elementar onde se via a presença de negros, criado e mantido por D Pedro II, Imperador do Brasil; em princípio, tinha o fim de acolher os filhos dos empregados da Casa Imperial e dos moradores da Imperial Quinta, o que demonstra que a educação dos escravos não era iniciativa exclusiva dos clubes e centros abolicionistas. Outra iniciativa do governo imperial foi estudada por Adriana Valentim Beaklini, confirmando a presença escrava na Escola Mixta da Fazenda Imperial de Santa Cruz, no Rio de Janeiro (BEAKLINI, 2013). Por seu turno, o trabalho de Maria Zélia Maia de Souza evidenciou a presença de "ingênuos" no Asilo de Meninos Desvalidos, "instituição asilar que fez parte do vasto conjunto 
heterogêneo de experiências a que a população de ingênuos, órfãos, pobres e/ou abandonados" teve acesso (SOUZA, 2013, p. 20).

Há também estudos sobre escolas mantidas por associações abolicionistas, voltadas para a educação de escravos e libertos. Nesse sentido, "Escolas de negros", de Monica Luise Santos e Maria das Graças Madeira, é uma importante referência. As autoras analisam a fundação da Escola Central, criada na cidade de Maceió (AL) pelos abolicionistas filiados à Libertadora Alagoana, em 1887, e pontuam que a escola tinha por finalidade "abrigar crianças negras do sexo masculino beneficiadas pela Lei do Ventre Livre" (SANTOS; MADEIRA, 2006, p. 50). A escola teve vida efêmera, sendo extinta aos seis anos de existência. Conforme as autoras,

[...] no ano de 1888, a Escola Central apresentava 81 alunos no ensino primário, 22 no ensino de música e 44 em desenho aplicado às artes. Nas oficinas, havia 28 alunos em marcenaria; alfaiataria e sapataria, ambas com 26; tornearia e tipografia, ambas com sete alunos; e nos ofícios de bauleiro, três; e para tamanqueiro, dois aprendizes" (SANTOS; MADEIRA, 2006, p. 57).

A abertura de escolas noturnas para libertos e escravos foi uma das ações de clubes abolicionistas situados na cidade do Rio de Janeiro e adjacências. A luta para a criação de creches para os filhos de escravos e libertos foi uma das ações empreendidas, por exemplo, pelo Clube dos Libertos de Niterói (VILLELA, 2012). Na cidade do Rio de Janeiro, Roseane Torres e Flávia Souza estudaram os projetos de grupos abolicionistas em torno da educação popular na localidade (TORRES; SOUZA, 2014).

Já em Pernambuco, em 1874, missionários capuchinos fundaram a Colônia Orfanológica Isabel, cuja finalidade era abrigar crianças órfãs e "ingênuas", meninos negros, brancos e índios (ARANTES, 2005). O problema da educação dos "ingênuos", a partir da Lei do Ventre Livre de 1871, foi estudado por diferentes pesquisadores (BARROS, 2013; MARTINEZ; PESSANHA, 2012; SILVA, 2014). Os estudos no âmbito da cultura letrada também procuram problematizar a aquisição e os usos da escrita por escravos e libertos. Tais investigações indicam a importância 
de documentos, como cartas e autobiografias, para a compreensão dos caminhos construídos pelos sujeitos em busca da liberdade. Todavia, quem escreve os textos dos escravos? Foram eles os próprios escritores? Onde essas pessoas aprenderam a escrever?

No artigo "Writing from the margins: brazilian slaves and written culture", Sandra Lauderdale Graham parte da análise de uma carta da liberta Florença da Silva para sua filha (a escrava de nome Balbina), a fim de problematizar os usos e a inserção dos escravos e libertos no universo da cultura escrita (GRAHAM, 2007). Por seu turno, Marialva Barbosa (2009) indica as diferentes formas de relação possíveis entre os escravos e a imprensa: desde aqueles que circulavam pelas ruas vendendo jornais até os escravos leitores de tais periódicos. A autora segue o rastro dos periódicos e dos anúncios para problematizar as representações produzidas sobre o cativo (BARBOSA, 2009).

Os múltiplos significados da escrita entre escravos e forros constituiu o foco de Maria Cristina Wissenbach, a partir da análise de cartas e procurações produzidas por escravos em São Paulo, na segunda metade do século XIX (WISSENBACH, 2002). A problematização em torno do processo de aquisição da leitura e da escrita e a apropriação de textos por escravos e libertos também foram objeto de análise em outros estudos (MORAIS, 2007; MOYSÉS, 1994).

A partir do balanço (sempre inconcluso e incompleto) da produção da temática educação de escravos e libertos (com destaque para a produção de História da Educação no Brasil), não foram localizados estudos específicos sobre a questão nos Estados Unidos, apesar da existência de fontes sobre o assunto em língua portuguesa. $O$ presente artigo procura, desse modo, contribuir com o debate, indicando a relevância da experiência de pessoas nascidas no cativeiro nos Estados Unidos, a partir dos impressos de origem autobiográfica. Afinal, qual a importância de se conhecer as trajetórias de sujeitos como Frederick Douglass, Booker Washington e Harriet Jacobs para a História da Educação no Brasil? 


\section{Meus anos de cativeiro e liberdade, por Frederick Douglass}

Redigidos em primeira pessoa, slave narratives são, de acordo com a Encyclopedia Britannica, "relatos de vida, ou de grande parte da vida, de um fugitivo ou ex-escravo, escritos ou oralmente, pelo próprio pelo sujeito". Tais narrativas constituem uma das mais influentes tradições na Literatura Americana, apresentando enredos controversos, tanto na ficção como na autobiografia, na história dos Estados Unidos ${ }^{3}$. Editada em dois volumes, The interesting narrative of the life of Olaudah ${ }^{4}$, de 1789, é considerada uma das primeiras narrativas de escravos a se tornar um best-seller internacional. Assim, "desde 1776 mais de 200 autobiografias de escravos libertos foram publicadas nos Estados Unidos e Inglaterra. Milhares de discursos gravados taquigraficamente, depoimentos e entrevistas com escravos e ex-escravos foram obtidos por jornalistas, acadêmicos e funcionários do governo" (MILLER; SMITH, 1988, p. 71).

Em 25 de abril de 1883, o jornal abolicionista Gazeta da Tarde apresentava Frederico (Frederick) Douglass em sua primeira página:

Amanhã Frederico Douglass começará a ser conhecido devidamente por aqueles que se interessam por uma raça desprezada e diariamente insultada por energúmenos, que trabalham por deitar por terra a propaganda em bem da causa dos oprimidos, mas que não conseguem destruir os vestígios luminosos que, como Douglass, um simples escravo, tornam-se governadores da terra onde viram a luz ainda envoltos nas trevas do cativeiro. É que a natureza os privilegia no nascedouro (Gazeta da Tarde, 25/04/1883, p. 1).

Naquele momento, tornar conhecida a vida de um ex-escravo nascido nos Estados Unidos tinha um sentido claramente pedagógico e político, no combate à escravidão ainda vigente no Brasil. A vida de Frederick Douglass ganhava ares de exemplaridade para os abolicionistas do jornal Gazeta da Tarde. Fundando, em 1880, pelo advogado e jornalista José

3 “Slave narrative." In: Encyclopedia Britannica, 2008. Disponível em: <http://global.britannica.com/ EBchecked/topic/548224/slave-narrative>. Acesso em: 19 jun. 2014.

4 Disponível em: <http://docsouth.unc.edu/neh/equiano1/equiano1.html>. Acesso em: 19 jun. 2014. 
Ferreira de Menezes, o jornal Gazeta da Tarde era reduto da militância abolicionista na década de 1880, na cidade do Rio de Janeiro, capital do Império brasileiro:

Sendo uma fonte indispensável para os estudos sobre o abolicionismo na corte, as abordagens sobre a Gazeta da Tarde, via de regra, se atêm à preocupação de seus editores com os problemas enfrentados por escravizados em busca de alforria e/ou tratamento digno. Ocorre, porém, que esse periódico foi também um espaço importante para a defesa da cidadania de livres e libertos, bem como veiculou muitos contrapontos ao "preconceito de cor" e ao "ódio de raça", verificados tanto em argumentos pseudocientíficos quanto em episódios do cotidiano (PINTO, 2015, p. 1).

As análises advindas dos periódicos ganham maior sustentação quando dialogamos com a produção acadêmica, que vem realizando interessantes estudos sobre a temática. As pesquisas desenvolvidas por Ana Flávia Magalhães Pinto sinalizam para a existência de muitos jornalistas negros na imprensa oitocentista e também para a experiência de literatos negros, com destaque para Ferreira de Menezes, Luiz Gama, Machado de Assis, José do Patrocínio, Ignácio de Araújo Lima, Arthur Carlos e Theophilo Dias de Castro (PINTO, 2015). Importante ressaltar que esses intelectuais participaram da luta contra o preconceito racial e pela ampliação dos direitos de cidadania, a partir dos usos da pena e da palavra impressa (PINTO, 2014). Investigações de Humberto Machado (1991; 2014) também se voltam para a imprensa abolicionista e seus projetos, nos quais se destacam análises sobre os periódicos $O$ Abolicionista, Gazeta da Tarde e Cidade do Rio, dentre outros.

Em maio de 1887, o jornal abolicionista Libertador anunciava a vontade de Frederick Douglass ${ }^{5}$ de conhecer o Brasil: “o senador dos Estados Unidos, Frederico Douglass, grande apostolo da abolição dos escravizados, tenciona, abandonando esta capital, dirigir-se à América do Sul e visitar especialmente o Brasil" (Libertador, 1887). Não se tem notícia se, de fato, o desejo foi realizado. Mas a presença de Frederick Douglass

5 O nome completo de Frederick Douglas era Frederick Augustus Washington Bailey. No Brasil, o jornal Gazeta da Tarde se referia a ele como "Frederico Douglass". 
no Brasil era anterior a 1887, como prova a tradução da autobiografia (1855) do ex-escravo que se tornou senador.

"My bondage and my freedom", de 1855, foi publicada pela Gazeta da Tarde em 1883. Nas palavras dos editores, a publicação do texto de Frederick Douglass em fascículos tinha um sentido de exemplaridade:

Pois é este livro que tem por título Meus anos de escravidão e de liberdade que vamos tornar conhecido dos nossos leitores aos quais apresentaremos uma historia de negrores e infâmias contada pelo próprio que as sofreu e nelas representou como paciente o papel de protagonista (Gazeta da Tarde, 25/04/1883, p. 1).

A tabela a seguir mostra a logística da apresentação dos fascículos no jornal Gazeta da Tarde.

\section{Tabela1 - Fascículos publicados ao longo dos meses de abril, maio e junho}

\begin{tabular}{|c|c|c|c|}
\hline Data & Título do capítulo & Data & Título do capítulo \\
\hline 27 de abril de 1883 & $\begin{array}{l}\text { Nascimento e paren- } \\
\text { tesco }\end{array}$ & 26 de maio de 1883 & Aprendo a ler \\
\hline 02 de maio de 1888 & $\begin{array}{l}\text { Separado de minha } \\
\text { avó }\end{array}$ & 29 de maio de 1883 & Progresso \\
\hline 07 de maio de 1883 & Pesares de criança & 30 de maio de 1883 & Progresso \\
\hline 08 de maio de 1883 & A fazenda & 30 de maio de 1883 & $\begin{array}{l}\text { O espírito desper- } \\
\text { tado }\end{array}$ \\
\hline 11 de maio de 1883 & O intendente & 31 de maio de 1883 & $\begin{array}{l}\text { O espírito desper- } \\
\text { tado }\end{array}$ \\
\hline 14 de maio de 1883 & Raciocínios de criança & 2 de junho de 1883 & $\begin{array}{l}\text { O espírito desper- } \\
\text { tado }\end{array}$ \\
\hline 15 de maio de 1883 & Contrastes & 4 de junho de 1883 & $\begin{array}{l}\text { O espírito desper- } \\
\text { tado }\end{array}$ \\
\hline 16 de maio de 1883 & Contrastes & 6 de junho de 1883 & $\begin{array}{c}\text { Vicissitudes da vida } \\
\text { escrava }\end{array}$ \\
\hline 17 de maio de 1883 & M: Austin Gore & 8 de junho de 1883 & $\begin{array}{c}\text { Vicissitudes da vida } \\
\text { escrava }\end{array}$ \\
\hline 18 de maio de 1883 & M: Austin Gore & 8 de junho de 1883 & Saint Michel \\
\hline 18 de maio de 1883 & Mudança de residência & 11 de junho de 1883 & Saint Michel \\
\hline 21 de maio de 1883 & Mudança de residência & 12 de junho de 1883 & Saint Michel \\
\hline
\end{tabular}




\begin{tabular}{|c|c|c|c|}
\hline 22 de maio de 1883 & Mudança de residência & 14 de junho de 1883 & Saint Michel \\
\hline 25 de maio de 1883 & Aprendo a ler & 15 de junho de 1883 & O cortador de negros \\
\hline
\end{tabular}

Fonte: Gazeta da Tarde, 1883

Ainda conforme o Gazeta da Tarde, Frederick Douglas superou a escravidão e tornou-se um exemplo, um importante orador na luta contra a escravidão e pela igualdade:

Frederico Douglass é uma dessas organizações heróicas e grandes. Nascido escravo na pátria de Washington e Lincoln, conservandose até a idade de 21 anos nessa condição, sofrendo todos os vexames, humilhações e castigos que costumam sofrer os escravos, Douglass conseguiu ser hoje considerado como escritor de mérito, orador veemente e o mais acérrimo defensor de sua raça (Gazeta da Tarde, 25/04/1883, p. 1).

O capítulo de abertura, "Nascimento e parentesco", apresenta as especificidades dos nascidos na escravidão. A imprecisão da data do nascimento é a primeira. Nas palavras de Douglass: "Minha idade! Muito difícil de saber. Nunca encontrei um escravo que soubesse a sua. Meus cálculos, entretanto, baseados em certos acontecimentos, dos quais conservei a data, fazem remontar o meu nascimento a fevereiro de $1817^{6 \prime}$ (apud Gazeta da Tarde, 1883, p. 2). Já a figura da avó materna é bastante presente no relato de Frederick Douglass: "Separado de minha avó" foi um momento traumático na vida do menino escravo que também desconhecia a identidade do pai:

Bastava a escravidão de minha mãe. A condição das mães fixa invariavelmente a condição dos filhos. Mãe escrava, filho escravo. Fosse o pai livre, o filho seria escravo. Que uma gota imperceptível de sangue africano circule nas veias da criança, o pai venderá o filho sem pestanejar (Gazeta da Tarde, 27/04/1883, p. 2).

A autobiografia publicada no jornal Gazeta da Tarde é uma síntese do texto original, editado em língua inglesa. No livro divulgado no jornal abolicionista, apenas uma visão geral das agruras na vida de um escravo

6 A data de nascimento de Frederick Douglass seria 14/02/1818, conforme site "Documenting the American South". 
nascido no nordeste dos Estados Unidos: desde a dor da separação dos entes queridos até castigos, humilhações e sofrimentos da infância, adolescência e vida adulta no cativeiro. Escravo desde o berço, no estado de Maryland, Frederick pertencia à família do coronel Lloyd, e muitos foram os que o aterrorizaram: Captain Aaron Anthony, Austin Gore, Sr. Andrew e Edward Covey.

Frederick Douglass escreveu ao menos três livros de cunho autobiográfico: Narrative of the life of Frederick Douglass, an american slave (1845); My bondage and my freedom (1855) e Life and times of Frederick Douglass (1881). As duas primeiras autobiografias foram publicadas durante a vigência da escravidão nos Estados Unidos, e a terceira foi editada no pós-abolição, nos Estados Unidos. A impressão dos fascículos no Brasil deu-se também durante a vigência da escravidão, que só foi abolida em $1^{\circ}$ de maio de 1888, 25 anos mais tarde que nos Estados Unidos. Em Meus anos de cativeiro e de liberdade (1883), Douglass evidencia a brutalidade do escravismo, mencionando diversos casos de abuso senhorial, na figura dos capatazes. Douglass também confere especial atenção ao modo pelo qual aprendeu a ler e a escrever. O acesso ao universo da leitura e da escrita foi a primeira experiência de liberdade praticada por Douglass, ainda na condição de cativo, antes da fuga. Tal aprendizado foi registrado nos capítulos "Aprendo a ler", "Progresso" e "Espírito despertado". Foi com a ajuda da senhora Sophia que Frederick Douglass deu os primeiros passos no mundo da leitura:

A força de ouvir mistress Sophia ler em voz alta o Evangelho, minha curiosidade redobrou. A leitura! Que mistério! Da curiosidade ao desejo de ler eu mesmo, não havia mais do que um passo, eu o confesso. Ousei pedir a minha senhora para ensinar-me essa arte maravilhosa. Ela consentiu, e apliquei-me tanto ao alfabeto, que com uma incrível presteza, soletrei sem hesitar as palavras de três e mesmo de quatro letras (Gazeta da Tarde, 26/05/1883, p. 2).

Aprender a ler não foi fácil para o menino Frederick, pois ele enfrentava o descontentamento do marido da senhora Sophia, que considerava bastante perigoso para a escravidão a existência de escravo instruído: 
O senhor Hugues, consternado, procedeu, sem perda de um instante, o ensino de sua mulher. Tratava-se de inculcar-lhe os verdadeiros princípios da escravidão: as regras a observar relativamente ao rebanho negro.

- Concedei uma polegada ao negro, ele tomará logo uma vara. Ensinai-lhe a ler hoje, amanhã ele escreverá e depois de amanhã libertar-se-á. Que um negro procure ler a Bíblia, e ele está perdido para a escravidão. $O$ negro não deve saber senão uma coisa: a vontade de seu senhor, não aprender senão outra: obedecê-lo. O que há de mais provem da malignidade. Sem contar que a instrução, faria do escravo um louco (Gazeta da Tarde, 26/05/1883, p. 2).

$\mathrm{O}$ acesso às letras ampliou a revolta de Douglass em relação à escravidão. Tornou-se leitor dos discursos de Sheridan, Chatam, Pitt e Fox: "Eu os lia, os relia. Ensinaram-me a dar uma linguagem ao meu pensamento. Os direitos do homem, de todo homem, vieram-me das palavras de Sheridan" (Gazeta da Tarde, 29/05/1883, p. 2). Para Douglass, "a palavra significava esperança", e os jornais abolicionistas tinham um papel emancipador. Inicialmente, Douglass aprendeu a ler. Depois, sem um mestre, aventurou-se nos caminhos da escrita e nunca mais parou:

Fui aperfeiçoando graças aos cadernos de Tommy, que a esse tempo era crescido e andava na escola. Esses cadernos, glória de família, eram mostrados aos amigos e parentes; e depois de receberem o justo tributo de elogios, eram guardados em um armário, do qual deixavam a chave na fechadura. Ficando muitas vezes na sala horas inteiras, corria aos cadernos, copiavalhes os textos entre as linhas arriscando-me a ser castigado, se descobrissem o atentado, mas sofrendo para saber, o que para mim era uma grande honra. Isso não era tudo. De noite, em meu reduto perto do paiol, um canto raras vezes visitado pelos senhores, levantara um barril vazio, uma cadeira perto e sobre esta mesa improvisada, escrevia, estudava, copiava passagens da Bíblia ou qualquer livro de Salmos. Meus professores eram, como se pode ver, ora as paredes do paiol, ora os meninos da cidade, ora os cadernos do filho da casa. Ora os meus caros volumes. Tio Lawson sustentava minha fé, via-o muitas vezes. Apesar das ameaças, o senhor Hugues não me havia ainda castigado. (Gazeta da Tarde, 2/06/1883, p. 2). 
Nos exemplares disponibilizados pela hemeroteca digital da Biblioteca Nacional não consta o final da narrativa de Frederick Douglass, de modo que apenas a parte relativa aos anos de cativeiro é contemplada. O tempo de escravo fugido e de liberdade não foi considerado. Também não se sabe quem traduziu e condensou o livro de Frederick Douglass. De acordo a pesquisadora Ana Flavia Pinto Magalhães (2015), a "interlocução internacional" de José do Patrocínio foi favorável à publicação de textos como os de Douglass, e a ponte entre as lutas pela liberdade nos Estados Unidos e no Brasil consolidou-se graças às páginas de jornais abolicionistas como o Gazeta da Tarde.

\section{Booker Washington e as memórias de um negro}

Up from slavery: an autobiography (1901) é o título de uma das três autobiografias escritas por Booker T. Washington; as outras intitulam-se: An autobiography. The story of my life and work (1901) e My larger education: being chapters from my experience (1911). Inicialmente, o relato de Booker Washington foi publicado, na forma de artigos, na revista Outlook; devido ao sucesso junto ao público, os outros dois livros foram lançados no ano de 1901. Mas por que Booker T. Washington editou duas autobiografias no mesmo ano?

Segundo Gledhiil (2014, p. 71), Up from slavery era dirigida a leitores brancos, enquanto An autobiography. The story of my life and work teria como público-alvo os negros. Up from slavery: an autobiography foi publicado pela Doubleday \& Company (Nova York), já An autobiography. The story of my life and work saiu pela J. L. Nichols \& Company (Naperville, Illinois). Booker T. Washington já foi explorado em muitos estudos acadêmicos nos Estados Unidos. No Brasil, a tese de Helen Sabrina Gledhill (2014) explora as trajetórias de Booker T. Washington e de Manuel Querino na luta contra as ideias racialistas:

No Brasil, a história de Booker T. Washington (1856/1915) é ainda mais desconhecida que a de Querino, embora sua autobiografia romanceada Up From Slavery tenha sido enfoque de uma resenha

7 Disponível em: <http:/ / docsouth.unc.edu/fpn/washington/washing.html>. Acesso em: 20 jan. 2014. 
detalhada publicada em várias edições do Diário da Bahia em 1902. Depois foi traduzida novamente por Graciliano Ramos com o título Memórias de um negro, lançado pela Editora Nacional em São Paulo em 1940 (GLEDHILL, 2014, p. 19).

A tradução de Up from slavery no Brasil ficou a cargo do alagoano Graciliano Ramos, romancista, contista, cronista e tradutor, além de Diretor da Instrução Pública. Dentre as obras traduzidas por Graciliano Ramos, destacam-se: La Peste (1947), de Albert Camus, e Memórias de um negro, de Booker Washington. Na perspectiva de Wellington Pereira, a analogia "entre a infância nordestina de Ramos e o relato de vida do norte-americano Washington é inevitável. Embora diferentes, em estilo, contexto e comprometimento racial, as duas obras retratam o período pós-abolição em grandes sociedades do continente americano" (PEREIRA, 2010, p. 7). Graciliano Ramos considerava importante divulgar, no Brasil, a vida de um sujeito que venceu a escravidão e que lutava pela ampliação dos direitos para o povo negro:

Contudo, não enxerguemos em Booker Washington um egoísta. Era um sujeito de ação, muito hábil. Nos Estados Unidos tomou lugar naturalmente entre os negros. $\mathrm{E}$ forçou-os a trabalhar com desespero, enquanto esfolava os brancos. Deseja dar ao preto independência econômica. O grego, o latim, as artes, as ciências, todos os enfeites internos de que ele próprio tinha vaga notícia, viriam depois (RAMOS, 1984, p. 214, apud PEREIRA, 2010).

A tradução de Graciliano Ramos seguiu a estrutura dos capítulos do livro original, publicado em 1901, totalizando 17 capítulos:

\section{Tabela 2 - Capítulos traduzidos por Graciliano Ramos e os originais de Up from slavery}

\begin{tabular}{|c|c|}
\hline Tradução & Original em inglês \\
\hline Memórias de um negro (1940) & Up from slavery, An autobiography (1901) \\
\hline Um escravo entre escravos & A slave among slaves \\
\hline Minha infância & Boyhood days \\
\hline Luta pela educação & The struggle for an education \\
\hline
\end{tabular}




\begin{tabular}{|c|c|}
\hline Auxilio aos outros & Helping others \\
\hline O despertador & The reconstruction period \\
\hline Negros e índios & Black race and red race \\
\hline Princípios de Tuskegee & Early days at Tuskegee \\
\hline Aulas numa estrebaria e num galinheiro & Teaching school in a stable and a hen-house \\
\hline Dias de angustia e noites de insônia & Anxious days and sleepless nights \\
\hline Uma tarefa difícil & A harder task than making bricks without \\
straw
\end{tabular}

Fonte: Pereira (2010)

"Um escravo entre escravos". Com essas palavras, Booker Washington inicia o Capítulo 1 de sua autobiografia. Nascido escravo em uma fazenda de Franklin County, Virgínia (sudeste dos Estados Unidos), o autor afirma não saber ao certo a data de seu nascimento:

Nasci escravo numa fazenda, em Flanklin, na Virgínia. Não sei com exatidão o lugar e a data do meu nascimento; creio, porém, que vim ao mundo em 1858 ou 1859, perto do Forte de Hale, encruzilhada onde havia uma agência do correio. Mês eu ignoro. As lembranças mais remotas que guardo ligam-se à fazenda, especialmente à parte dela ocupada pelos escravos, a senzala (WASHINGTON, 1940, p. 1).

Assim como Frederick Douglass, Booker Washington descreve os tempos de cativeiro como terríveis, miseráveis, de total e completa desolação para os escravos. Logo menciona o fato de que, após a Guerra Civil Americana (1861/1865), foi declarado livre; portanto, viveu parte da infância como escravo. Se, por um lado, Booker Washington menciona 
a mãe e o irmão, por outro, silencia-se quanto ao pai, a respeito do qual diz nada saber (WASHINGTON, 1901, p. 3). Acredita-se que o pai de Booker Washington tenha sido um branco desconhecido; apesar de Booker Washington firmar-se sempre como negro, muitos, na época, chamavam-no de "mulato" (GLEDHILL, 2014, p. 43). Na condição de criança escrava, Booker lamentava não ter frequentado a escola quando menino:

Eu não tive escolarização enquanto fui um escravo. Mas, eu me lembro que fui muitas vezes até a porta da escola, carregando os livros de uma das pequenas donas da gente - e algumas dúzias de meninas e meninos numa classe, estudando, muito me impressionaram: aquilo era um céu (WASHINGTON, 1940, p. 5).

O primeiro contato de Washington com as letras e os números foi quando ele trabalhava em uma fábrica de sal, pois cada pacote de sal possuía um número:

Cada pacote de sal tinha seus barris marcados com certo número. O número atribuído ao meu padrasto era " 18 ". No final do trabalho do dia o chefe dos embaladores viria ao redor e colocar " 18 " em cada um dos nossos barris, e logo aprendi a reconhecer tais figuras, e depois de um tempo chegou a um ponto onde eu podia fazer essa figura (WASHINGTON, 1901, p. 28).

Nas palavras de Booker Washington, a vontade de aprender era maior do que ele. Assim, "ainda quando era muito pequeno, decidi que eu precisava de alguma educação que me fizesse ser capaz de ler livros comuns e jornais" (WASHINGTON, 1901, p. 28). E prossegue:

Muito cedo me veio um forte desejo de aprender leitura. Pensei que, se nada conseguisse na vida, isso me daria pelo menos a satisfação de ler jornais e livros ordinários. Apenas instalados em nossa cabana da Virgínia Ocidental, pedi a minha mãe que arranjasse um livro. De qualquer forma, ela o achou e onde achou não sei, mas a verdade é que me trouxe um livrinho antigo de Webster, um folheto de capa azul que encerrava o alfabeto e sílabas sem sentido, como ab, ba, ca, da. Comecei a devorar essa brochura, a primeira que me caiu nas mãos. Tinham-me dito que era preciso conhecer o abecedário e esforcei-me tenazmente por 
aprendê-lo, sem mestre. (WASHINGTON, 1940, p. 20).

Em sua luta pela educação, Booker Washington seguia obstinado a frequentar uma escola e a receber instrução formal. Enquanto trabalhava em uma mina de carvão, ouviu dois mineiros conversarem a respeito de uma grande escola para coloured people (pessoas de cor), situada em algum lugar na Virgínia, no sudeste dos EUA (WASHINGTON, 1991, p.42). A escola em questão era a Hampton Normal and Agricultural Institute, e, em 1872, Booker T. Washington passou a frequentá-la:

Finalmente o grande dia chegou, e comecei a estudar na Hampton. Eu tinha apenas uma pequena mochila barata que continha os poucos artigos de roupa que possuía. Minha mãe na época estava bastante fraca e debilitada de saúde. Eu não esperava vê-la de novo, e, assim, nossa despedida foi ainda mais triste. Ela, no entanto, foi muito corajosa por tudo isso (WASHINGTON, 1940, p. 34).

Dispondo de poucos recursos, relata que recebia algum dinheiro que o irmão mais velho lhe enviava, mas que ainda assim precisava trabalhar para pagar seus estudos na Hampton (WASHINGTON, 1901, p. 59). Além da dificuldade para custear a mensalidade e a taxa anual de matrícula, o narrador ainda acrescenta a falta de livros para estudar, além de roupas e sapatos. Contudo, relata que muitos alunos enfrentavam situação parecida ou pior que a dele:

Eu estava entre os mais novos estudantes de Hampton naquele tempo. A maioria dos estudantes era de homens e mulheres com mais de quarenta anos de idade [...]. Quase todos tiveram contato real com o mundo o suficiente para ensinar-lhes a necessidade da educação. Muitos tinham mais dificuldade para dominar os textos dos livros didáticos, e muitas vezes, era triste ver suas lutas; mas faziam com muita seriedade muito do que lhes faltava nos livros. Muitos deles eram tão pobres como eu era, e, além de ter que lutar com seus livros, eles tiveram que lutar contra a pobreza. Muitos deles tinham pais idosos que eram dependentes deles, e alguns deles eram homens que tinham esposas cujo sustento de alguma forma eles tinham que prover (WASHINGTON, 1901, p. 62). 
Após concluir os estudos de três anos na Hampton, Booker Washington tornou-se professor; estudando ainda por mais um ano no Seminário Weyland, em Washington, DC:

No outono de 1878, após ter ensinado em uma escola em Malden por dois anos, e ter tido sucesso preparando vários jovens, homens e mulheres, além dos meus dois irmãos, a entrar no Hampton Institute, eu decidi gastar alguns meses de estudo no Washington D.C. Eu me lembro que foram oito meses lá (WASHINGTON, 1901, p. 87)

Após essa etapa de formação, Booker Washington relata que continuou atuando como professor em uma escola noturna, até que, no ano de 1881, foi convidado para lecionar na Escola Normal para pessoas negras, em Tuskegee:

Cheguei a Tuskegee em junho de 1881. O primeiro mês eu gastei procurando acomodação para a escola e viajando através do Alabama, examinando a atual condição de vida das pessoas, especialmente nos distritos rurais, e anunciando a escola entre a classe de gente que eu desejava atender (WASHINGTON, 1901, p. 112).

Além da tradução do livro, a presença do educador Booker Washington deu-se em diferentes momentos na imprensa periódica brasileira. O Correio da Manhã de 2 de setembro de 1956 trazia a seguinte matéria:

Centennial of Booker T. Washington

Para comemorar o centenário do nascimento de um dos maiores educadores da história dos Estados Unidos, Booker Taliaferro Washington, o Departamento dos Correios desse país pôs a venda um selo de 3 centavos. Foram emitidos cento e vinte milhões de exemplares do novo selo, que é azul, tendo no centro uma cabana semelhante àquela onde nasceu Booker Washington, e na parte inferior, as palavras Centenário de Booker Washington. Nascido numa plantação do sul de Franklin, na Virgínia, em abril de 1856, Booker Washington trabalhou ainda criança em minas de carvão. Matriculou-se mais tarde no Instituto Normal e Agrícola Hampton, onde trabalhava para pagar seus estudos. Foi pedreiro e mais tarde, professor (Correio da Manhã, 2/09/1956). 
O tom da narrativa de vida de Booker T. Washington foi o da educação como caminho para a superação da escravidão.

\section{Harriet Jacobs: a condição de mulher e escrava no século XIX}

Além das autobiografias de Frederick Douglass e Booker Washington, foi analisada, neste artigo, a autobiografia de Harriet Ann Jacobs, Incidentes da vida de uma escrava, contados por ela mesma, publicada, no Brasil, em 1988 (Editora Campus). Linda Brent é a narradora de Incidents in the life of a slave girl. Written by herself, publicado originalmente, em língua inglesa, no ano de 1861. Linda Brent é o alter ego de Harriet Ann Jacobs, nascida escrava, nos Estados Unidos, em 1813. No prefácio escrito pela autora (assinado como Linda Brent) em 1861, destaca que optou por pseudônimos, o que não significa que sua obra seja ficção:

Leitor, podes ter certeza de que esta narrativa não é fictícia. Sei que algumas de minhas aventuras podem parecer inacreditáveis, mas apesar disso são rigorosamente verídicas. Não exagerei os males causados pela Escravidão; pelo contrário, minhas descrições ficam muito aquém dos fatos. Ocultei os nomes dos lugares e dei nomes fictícios às pessoas. Não tinha motivos para ser reservada em relação a mim mesma, mas julguei que seria um ato de bondade e consideração para com os outros adotar essa atitude (JACOBS, 1988, p. 23).

A autobiografia de Harriet Jacobs (traduzida em língua portuguesa em 1988 e publicada pela editora Campus) foi organizada e editada por Jean Fagan Yellin, que também escreve a introdução mais recente da obra. O livro apresenta-se assim estruturado: prefácio, de Harriet Jacobs; introdução, de Lydia Maria Child ${ }^{8}$, e 41 capítulos. Apresenta também ilustrações e correspondências, ativas e passivas, de Harriet. Foi a partir das cartas de Harriet que a historiadora Jean Fagan Yellin evidenciou que se tratava de escrita em primeira pessoa de uma escrava, e não de uma "falsa narrativa de escravo". A partir das cartas de Harriet Jacobs, é

8 Lydia Maria Child (1802-1880) foi escritora, editora, jornalista e abolicionista. 
possível concluir o papel desempenhado por Lydia Maria Child, revisora, e não autora da obra. Nas palavras da própria Child:

A seu pedido, revi o original, mas as modificações que fiz visaram mais aos meus objetivos de condensação e disposição lógica. Não acrescentei nada aos incidentes, nem modifiquei o conteúdo de suas observações muito pertinentes. Com insignificantes exceções, tanto as ideias como a linguagem são dela. Podei um pouco as excrescências, mas não tive, agora isso, razões para modificar a maneira viva e dramática de contar sua história (CHILD, 1988, apud JACOBS, 1988, p. 24).

A publicação da primeira edição do livro, no século XIX, deu-se por iniciativa própria da autora. A autobiografia de Harriet Jacobs é considerada a principal escrita em primeira pessoa de uma mulher negra, cunhada antes da Guerra Civil nos Estados Unidos (1861-1865). Harriet Ann Jacobs viveu e morreu no século XIX (1813-1897). Nascida em cativeiro, na Carolina do Norte (sudeste dos EUA), fugiu para Nova York em 1842, onde lutou pelo fim da escravidão nos Estados Unidos e fez uso da palavra para contar sua experiência, em sua autobiografia. A experiência de Harriet Jacobs foi vastamente estudada nos Estados Unidos, sendo Jean Fagan Yellin uma referência importante. Yellin escreveu trabalhos como "Written by herself: Harriet Jacobs's slave narrative", artigo publicado na American Literature 53 (nov. 1981), e a biografia Harriet Jacobs: a life (2004). Também organizou a coletânea de documentos The Harriet Jacobs family papers (2008). Na introdução de Incidentes da vida de uma escrita, escrito por ela mesma, Jean Yellin afirma:

O feito de Harriet foi transformar-se em assunto literário com a, e através da, criação de sua narradora, Linda Brent. Essa narradora conta uma dupla história, dramatizando o triunfo dos seus esforços para evitar que seu senhor a estuprasse, para salvar dele os seus filhos, para esconder-se, para fugir e, finalmente, para conseguir a liberdade. E ao mesmo tempo, apresentando sua incapacidade de seguir os padrões sexuais em que acreditava. Solteira, ela estabelece uma ligação sexual, engravida, é condenada pela avó, e sofre culpa terrível (YELLIN, 1988, apud JACOBS, 1988, p. 3). 
No Brasil, destaco os trabalhos de Abreu (2006) e de Farias (2012), dissertações de mestrado defendidas na Universidade do Estado do Rio de Janeiro que exploram diferentes aspectos nas narrativas de escravas mulheres nos Estados Unidos.

Quanto à condição feminina e à especificidade da mulher escrava, são marcas fortes no relato de Linda Brent (Harriet Jacobs). A menina escrava, muitas vezes, serve de boneca para as crianças brancas:

Vi, certa vez, duas belas crianças brincando juntas. Uma era loura e branca; a outra era a sua escrava e também sua irmã. Quando as vi se abraçarem e ouvi sua risada alegre, afastei-me com tristeza daquele belo quadro. Previa a desgraça inevitável que cairia sobre o coração da pequena escrava. Sabia como o seu riso se transformaria em soluços dentro em pouco. A criança loura cresceu e transformou-se numa mulher ainda mais bela. Da infância à condição adulta, seu caminho estava cheio e coberto por um céu ensolarado. [...] E como teriam sido esses anos para a sua irmã escrava, a pequena companheira de sua infância? Também era muito bela, mas as flores e o sol do amor não existiam para ela (JABOCS, 1988, p. 44).

Na adolescência, muitas escravas sofriam com o assédio e a violência sexual por parte dos senhores; além de perseguição e ciúme, por parte das senhoras:

Quer a escrava seja negra como ébano ou branca como sua senhora, a situação é a mesma. Em ambos os casos, nenhuma sombra da lei a protege contra insultos, violências e nem mesmo da morte; tudo isso lhe é imposto por demônios que têm a forma de homens. A senhora, que deveria proteger a vítima indefesa, só tem com ela sentimentos de ciúme e raiva (JACOBS, 1988, p. 42).

A escrava mãe, por sua vez, sofria com a separação dos filhos:

Ó felizes mulheres livres, comparem o seu dia do Ano-Novo com o da pobre mulher cativa! Para vocês é uma época agradável, e a luz do dia é bendita [...]. Mas para a mãe escrava o dia do Ano-Novo está carregado de sofrimentos peculiares. Ela fica sentada no frio chão de sua cabana, vendo os filhos que podem ser arrancados dela na manhã seguinte; e com freqüência deseja que possam morrer antes que o dia amanheça. Pode ser uma criatura ignorante, 
degradada pelo sistema que a brutalizou desde a infância; mas tem o instinto materno e é capaz de sofrear as agonias de mãe (JACOBS, 1988, p. 33).

Para Yellin:

$\mathrm{Na}$, e através da criação de Linda Brent, que combina sua história de êxitos como heróica mãe escrava com sua confissão de mulher que lamenta não ser uma heroína de livros de história, Harriet articula sua luta para afirmar sua condição feminina e projetar um novo tipo de heroína (JACOBS, 1988, p. 4).

Harriet Jacobs foi aconselhada pelo bispo Paine a publicar um esboço biográfico, no que também era relutante, a exemplo de Amanda: "Quando eu cheguei à Filadélfia, o bispo Paine aconselhou-me a publicar um esboço de minha vida, mas eu lhe disse que era totalmente incompetente para tal empresa" (JACOBS, 1988, p. 23). A esse respeito, Harriet afirmava:

Não escrevi as minhas experiências a fim de atrair a atenção para mim; pelo contrário, ter-me-ia sido mais agradável silenciar sobre minha história. Também não me preocupo em despertar simpatias para meus sofrimentos. Mas desejo sinceramente despertar as mulheres do Norte para a compreensão das condições de dois milhões de mulheres no Sul, ainda no cativeiro, sofrendo o que sofri, e a maioria delas, mas ainda. Quero acrescentar meu testemunho ao de penas mais capazes de convencer as pessoas dos Estados Livres do que a Escravidão realmente é (JACOBS, 1988, p. 23).

Harriet Jacobs não se casou. Envolveu-se com um homem branco da região e foi mãe solteira de duas crianças. A escrita autobiográfica de Harriet Jacobs é considerada, pelo The New York Time, "um opúsculo feminista", pois a autora luta duplamente: para se libertar da escravidão e da opressão contra as mulheres. Harriet Jacobs, em vários momentos, dirigia-se à leitora livre, reconhecendo um vínculo entre as mulheres: a opressão masculina. Para Harriet, a liberdade estava em construção, e sua escrita era mais uma na luta pelo fim da escravidão e pela igualdade entre homens e mulheres. 


\section{Considerações finais}

Em diferentes momentos, as narrativas de vida dos ex-escravos foram consideradas dignas de serem conhecidas no Brasil. Ainda no século XIX, pela ausência de histórias similares no Brasil, os abolicionistas do jornal Gazeta da Tarde, liderados por José do Patrocínio, promoveram a publicação, na forma de fascículos, do livro escrito por Frederick Douglass, defendo a hipótese de que, para além do reconhecimento da importância do nome Frederick Douglass em prol da causa abolicionista, publicar e divulgar uma autobiografia escrita por um sujeito nascido escravo tinha um sentido pedagógico e mesmo de exemplaridade. Possivelmente, os abolicionistas brasileiros nutriam o desejo de que narrativas como as de Douglass, mas com escravos nascidos no Brasil, fossem também escritas e divulgadas. A ousadia dos abolicionistas brasileiros era grande, pois, em 1883, a escravidão ainda perdurava no Brasil. Desse modo, traduzir e publicar em um veículo como o jornal (mais barato e acessível) tais textos foi uma forma de tornar conhecida pelo grande público a vida de um cativo que superou a escravidão.

Da publicação de Meus anos de cativeiro e de liberdade às Memórias de um negro, passaram-se quase 60 anos. É interessante notar que o livro de Booker Washington foi publicado no pós-abolição (tanto nos Estados Unidos como no Brasil). O significado dessa obra é, portanto, distinto do livro de Frederick Douglass. A tradução de Memórias de um negro inscreve-se na luta por direitos e pela igualdade plena, no pós-abolição, para além da liberdade do cativeiro. Já a tradução em português do livro de Harriet Jacobs ocorreu no Brasil em 1988, 48 anos após Memórias de um negro, de Washington. Incidentes na vida de uma escrava foi publicado no Brasil no mesmo ano da Constituição de 1988, momento de intensificação das lutas dos movimentos sociais e dos negros em nosso país.

Ao término deste artigo, defendo que, nos três casos analisados, o uso da escrita para tornar pública a experiência de vida, na busca por emancipação e conquista de direitos, foi o ponto de aproximação comum a todos. Compreendo que as traduções das autobiografias de Frederick Douglass, Booker Washington e Harriet Jacobs estão inscritas 
em temporalidades e espacialidades distintas; todavia, o terreno da luta pela superação do racismo e das desigualdades nas relações étnico-raciais é um ponto de união.

Pensando o caso brasileiro, por caminhos diferentes, há estudos que partem de diferentes fontes (manuscritos, em grande parte) e que procuram explorar e dar visibilidade à trajetória de sujeitos que, nascidos escravos, ascenderam socialmente por meio da educação (MAC CORD, 2014). Mesmo não tendo nascido escravo, mas escravizado em venda ilegal realizada pelo próprio pai, a trajetória do intelectual Luiz Gama é outro caso em que o acesso à educação foi um caminho para a construção da liberdade (SOUZA, 2001).

O conhecimento de trajetórias de ex-escravos é necessário no Brasil, país em que a memória é um direito negado à maior parte de sua população afrodescendente. Conhecer outras histórias e outras experiências é uma forma de olharmos para dentro e de interrogarmos o processo de silenciamento e de negação da nossa própria constituição e identidade. Estudar e conhecer trajetórias como as de Harriet Jacobs, Frederick Douglass e Booker Washington, portanto, torna-se caminho essencial para uma História da Educação, no plural.

\section{Referências}

ABREU, Aline. Celebrating womanhood and motherhood in (post) slave narratives: a contemporany reading of Harriet Jacobs's Incidents in the life of a slave girl and Maya Angelous's I know why the bird sings. Dissertação (Mestrado em Literatura Inglesa) - UERJ, Rio de Janeiro, 2006.

ARANTES, Adlene Silva. O papel da Colônia Orfanológica Isabel na educação e na definição dos destinos de meninos negros, brancos e índios na Província de Pernambuco (1874-1889). Dissertação (Mestrado em Educação) - Universidade Federal de Pernambuco, Recife, 2005.

BARBOSA, Marialva. Escravos letrados: uma página (quase) esquecida. 
E-Compós, Brasília, DF, v. 12, p. 1-19, 2009.

BARROS, Karla Alves Coelho Tertuliano de. Educação e “Ingênuos" em Goiás: 1871-1888. Dissertação (Mestrado em Educação) - Universidade Federal de Goiás, Campus Catalão, 2013.

BARROS, Surya Aaronovich Pombo de. Negrinhos que por ahi andão: escolarização da população negra em São Paulo (1870-1920). Dissertação (Mestrado em Educação) - Faculdade de Educação, Universidade de São Paulo, São Paulo, 2005a.

Fontes para a História da Educação da População Negra em São Paulo. In: REUNIÃO ANUAL DA ANPED, 28., 2005, Caxambu. Anais da $28^{\text {a }}$ Reunião Anual da ANPEd. Caxambu: ANPEd, 2005b. v. 1. p. 1-16.

BEAKLINI, Adriana. Escola Mixta da Imperial Fazenda de Santa Cruz: uma proposta de educação pelo trabalho do Imperador D. Pedro II (18851889). Dissertação (Mestrado em Educação) - Universidade Federal do Estado do Rio de Janeiro, Rio de Janeiro, 2013.

BLASSINGAME, John W. Slave testimony: two centuries of letters, speeches, interviews and autobiographies. Baton Rouge: Louisiana State University Press, 1977.

CARVALHO, Luiza Helena de. João de Mattos: as aventuras de um padeiro na luta pela liberdade e pela dignidade da profissão (1876-1912). Dissertação (Mestrado em História) - Universidade do estado do Rio de Janeiro, Rio de Janeiro, 2009.

DAVIS, Charles; GATES JR, Henry Louis. The slave's narrative. New York: Oxford University Press, 1985.

DOUGLASS, Frederick. Life and times of Frederick Douglass. Boston: De Wolfe \& Fiske Co.,1892. 
. My bondage and my freedom. New York: Miller, Orton \& Mulligan, 1855.

Narrative of the life of Frederick Douglass, an american slave. Boston: Anti-slavery Office, 1845.

FARIAS, Adriana Merly. Female slave narratives consistency and permanence: a study of two texts from the XIX ${ }^{\text {th }}$ and $X X^{\text {th }}$ centuries. Dissertação (Mestrado em Literatura Inglesa) - Universidade do Estado do Rio de Janeiro, Rio de Janeiro, 2012.

FONSECA, Marcus V. Pretos, pardos, crioulos e cabras nas escolas mineiras do século XIX. Tese (Doutorado em Educação) - Universidade de São Paulo, São Paulo, 2007.

GLEDHILL, Sabrina. Travessias racialistas no Atlântico Negro: reflexões sobre Booker T. Washington e Manuel R. Querino. Tese (Doutorado em Estudos Étnicos) - Universidade Federal da Bahia, Salvador, 2014.

GRAHAM, S. Writing from the margins: Brazilian slaves and written culture. Comparative studies. Society and History, n. 49, p. 611-636, 2007.

HAGER, Christopher. Word by word: emancipation and the act of writing. Cambridge/Mass: Harvard University Press, 2013.

JACOBS, Harriet. Incidentes na vida de uma escrava, contados por ela mesma. Rio de Janeiro: Campus, 1988.

Incidents in the life of a slave girl. Written by herself. Boston: Published for the author, 1861.

LOPES, Katia Geni Cordeiro. A presença de negros em espaços de instrução elementar da cidade corte: o caso da Escola da Imperial Quinta da Boa Vista. Dissertação (Mestrado em Educação) - Programa de PósGraduação em Políticas Públicas e Formação Humana, Universidade do Estado do Rio de Janeiro, Rio de Janeiro, 2012. 
MARTINEZ, André Cruz; PESSANHA, Andréa Santos. Gazeta Nacional e a educação de ingênuos. Imprensa do Rio de Janeiro, 1888. In: ENCONTRO REGIONAL DE HISTÓRIA ANPUH-RIO, 15., 2012, São Gonçalo. Anais do XV Encontro Regional de História da ANPUH-Rio. Rio de Janeiro: ANPUH-Rio, 2012. p. 1-8.

MILLER, Randall; SMITH, John. Dictionary of afro-american slavery. Westport, Connecticut: Greenwood Press, 1988.

MORAIS, Christianni Cardoso. Ler e escrever: habilidades de escravos e forros? Comarca do Rio das Mortes, Minas Gerais, 1731-1850. Revista Brasileira de Educação, Rio de Janeiro, v. 12, n. 36, set./dez. 2007.

MOTT, Luiz. Uma escrava no Piauí escreve uma carta. Mensário do Arquivo Nacional, Rio de Janeiro, v. 11, n. 5, p. 3-21, 1979.

MOYSÉS. Sarita M. A. Leitura e apropriação de textos por escravos e libertos no Brasil do século XIX. Revista de Ciência e Educação Educação e Sociedade, São Paulo, n. 48, ago. 1994.

OLNEY, J. I was born: slave narratives, their status as autobiography and as literature. In: DAVIS, Charles T.; GATES JR., Henry Louis (Org.). The slave's narrative. New York: Oxford University Press, 1990. p. 148-175.

PEREIRA, Wellington Gustavo. Infância, de Graciliano Ramos: um relato dentro do período pós-abolição. Dissertação (Mestrado em Teoria Literária e Literatura Comparada) - Universidade do Estado de São Paulo, São Paulo, 2010.

PINTO, Ana Flávia Magalhães. Para quem quiser ver: cidadania negra e preconceito de cor nas páginas da Gazeta da Tarde (1880-1887). In: ENCONTRO ESCRAVIDÃO E LIBERDADENO BRASIL MERIDIONAL, 7., 2015, Curitiba. Anais do $7^{\mathbf{0}}$ Encontro Escravidão e Liberdade no Brasil Meridional. Curitiba: UFP, 2015.

. Fortes laços em linhas rotas: literatos negros, racismo 
e cidadania na segunda metade do século XIX. Tese (Doutorado em História) - Universidade Estadual de Campinas, Campinas, SP, 2014.

RAWICK, George. The american slave: a composite autobiography. Westport, Conn.: Greenwood Press, 1972.

SANTOS, Monica Luise; MADEIRA, Maria das Graças de Loiola. Escola de negros. In: CAVALCANTI, Bruno César et. al. (Org.). Kulé Kulé. Maceió: EDUFAL, 2006. p. 51-61.

SCHUELER, Alessandra F. M.;RIZZINI, Irma; MARQUES, Jucinato. Felismina e Libertina vão à escola: notas sobre a escolarização nas freguesias de Santa Rita e Santana (Rio de Janeiro, 1888-1906). História da Educação, Porto Alegre, v. 19, p. 145-165, 2015.

SEBRÃO, Graciane Daniela. Educação dos negros em Santa Catarina: narrativas, expectativas, experiências (1850-1889). Tese (Doutorado em Educação) - Programa de Pós-Graduação em Educação, Universidade do Estado do Rio de Janeiro, Rio de Janeiro, 2015.

SILVA, Adriana M. Paulo. Aprender com perfeição: escolarização e construção da liberdade na Corte na primeira metade do século XIX. Brasília, DF: Plano, 2002.

SILVA, Noemi Santos da. O batismo na instrução? Projetos e práticas de instrução formal de escravos, libertos e ingênuos no Paraná provincial. Dissertação (Mestrado em Educação) - Universidade Federal do Paraná, Curitiba, 2014.

SOUZA, Maria Cecília Cortez Christiano de. O preto no branco: a trajetória de escritor de Luiz Gama. In: VIDAL, Diana Gonçalves; HILSDORF, Maria Lúcia Spedo (Org.). Brasil 500 anos. Tópicos em História da Educação. São Paulo: EDUSP, 2001. p. 97-117.

SOUZA, Maria Zélia. Educar o jovem para ser "útil a si e a sua pátria": a assistência pela profissionalização, Rio de Janeiro (1894-1932). Tese 
(Doutorado em Educação) - Universidade Federal de Minas Gerais, Belo Horizonte, 2013.

TORRES, Roseane; SOUZA, Flávia. Liberdade e instrução: projetos e iniciativas abolicionistas para a educação popular (Rio de Janeiro, década de 1880). Contra Capa, Rio de Janeiro, v. 1, p. 49-84, 2014.

VEIGA, Cynthia Greive. Escola pública para os negros e os pobres no Brasil: uma invenção imperial. Revista Brasileira de Educação [online], v. 13, n. 39, p. 502-516, 2008.

VILLELA, Heloísa. O movimento abolicionista Niteroiense, o Clube dos Libertos e o projeto de uma creche para filhos de escravos e ex-escravos. 7., 2013, Cuiabá. Anais do $7^{\circ}$ Congresso Brasileiro de História da Educação. Cuiabá: SBHE; UFMT, 2013.

WASHINGTON, Booker T. Memórias de um negro. Trad. Graciliano Ramos. São Paulo: Companhia Editora Nacional, 1940.

My larger education: being chapters from my experience. Garden City, NY: Doubleday; Page, 1911.

. Up from slavery: an autobiography. Garden Citu, NY: Doubleday \& Company Inc., 1901.

. The story of my life and work. Cincinnati, Ohio: W.H. Ferguson Company, 1900.

WISSENBACH, Maria Cristina. Cartas, procurações, escapulários e patuás: os múltiplos significados da escrita entre escravos e forros na sociedade oitocentista. Revista Brasileira de História da Educação, São Paulo, n. 4, jul./dez. 2002. 